\title{
Corinne Denoyelle, Poétique du dialogue médiéval
}

\author{
Maria Colombo Timelli
}

\section{(2) OpenEdition}

\section{Journals}

\section{Édition électronique}

URL : http://journals.openedition.org/studifrancesi/3626

DOI : 10.4000/studifrancesi.3626

ISSN : 2427-5856

\section{Éditeur}

Rosenberg \& Sellier

\section{Édition imprimée}

Date de publication : 1 décembre 2012

Pagination : $537-538$

ISSN : 0039-2944

\section{Référence électronique}

Maria Colombo Timelli, «Corinne Denoyelle, Poétique du dialogue médiéval », Studi Francesi [En ligne], 168 (LVI | III) | 2012, mis en ligne le 30 novembre 2015, consulté le 08 mars 2021. URL : http:// journals.openedition.org/studifrancesi/3626 ; DOI : https://doi.org/10.4000/studifrancesi.3626

Ce document a été généré automatiquement le 8 mars 2021.

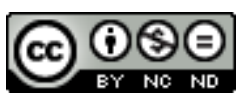

Studi Francesi è distribuita con Licenza Creative Commons Attribuzione - Non commerciale - Non opere derivate 4.0 Internazionale. 


\title{
Corinne Denoyelle, Poétique du dialogue médiéval
}

\author{
Maria Colombo Timelli
}

\section{RÉFÉRENCE}

CORINNE DENOYELLE, Poétique du dialogue médiéval, Rennes, Presses Universitaires de Rennes, 2010, pp. 374.

1 Cet ouvrage repose sur deux prémisses: le constat d'une présence abondante du dialogue dans les œuvres narratives du Moyen Âge et l'existence d'une logique et d'une écriture qui lui sont propres. C.D. se propose donc d'offrir une description précise du dialogue en tant que "production écrite et inscrite dans un contexte littéraire donné» dont on puisse dégager une sorte de "grammaire» (p.11). Le corpus-dont malheureusement ne sont nulle part explicités les critères de sélection - comprend des romans en vers et en prose produits entre $\mathrm{XII}^{\mathrm{e}}$ et $\mathrm{XIII}^{\mathrm{e}}$ siècle auxquels s'ajoutent les deux versions anciennes de La fille du comte de Pontieu et La Châtelaine de Vergy (liste des œuvres dans la première section de la bibliographie, p. 351).

2 L'analyse est organisée en deux parties. La première (La contextualisation des dialogues) prend en compte la manière dont les auteurs exposent les situations où les dialogues se déroulent: «cadre situationnel», à savoir spatial et temporel (chapitre I); «cadre participatif»: nombre des intervenants, dilogues / polylogues (chapitre II); «cadre thématique», comprenant sujets et buts des conversations (chapitre III); "cadre nonverbal», où sont pris en compte attitudes, gestes, mimiques (chapitre IV).

3 La seconde partie est consacrée à l'analyse interne du dialogue. Le «style oralisé» (chapitre V) comprend les éléments paraverbaux (description de la voix, imitation de l'oral dans les paroles des personnages); la «construction des dialogues» (chapitre VI) examine les répliques et leur «tempo»; la «syntaxe du dialogue» (chapitre VII) concerne plus précisément l'organisation des échanges: binaires, ternaires et leurs combinaisons et procédés d'étouffement. Un dernier chapitre vérifie les rapports éventuels des 
dialogues romanesques avec des «modèles institutionnels» (aveu judiciaire, confession et enseignement scolaire et religieux) et avec d'autres formes polémiques (jeux-partis et disputationes).

4 La Bibliographie, très riche, est raisonnée: outre les œuvres médiévales - corpus et autres textes consultés - elle comprend les sections «Linguistique générale et Pragmatique», «Histoire de la langue et Linguistique appliquée à l'ancien français», «Le dialogue romanesque: études générales et théoriques», "Histoire de la société médiévale», «Théorie et esthétique littéraires; histoire de la littérature», et «Ouvrages ou articles portant sur des domaines spécifiques» (pp.351-367); elle est suivie d'un Index des auteurs et œuvres cités et de quelques mots-clés.

Il serait difficile de résumer les résultats de ces analyses sans trop simplifier: certes, des différences se remarquent entre romans en vers et romans en prose qui ne dépendent pas nécessairement des contraintes prosodiques, un point de bascule se situant en gros au XIII ${ }^{e}$ siècle, lorsque les pratiques de lecture se modifient aussi. Par ailleurs, la part de l'auteur ou des auteurs est aussi à prendre en compte, comme le prouvent certaines caractéristiques du Tristan en prose ou du Merlin, qui isolent ces deux romans au sein du corpus examiné.

6 Ce livre a, parmi d'autres mérites, celui de la clarté: sans jamais jargonner, C.D. expose toujours les présupposés théoriques retenus et la nomenclature adoptée; les exemples cités sont pertinents et bien analysés. D'autre part, il y aurait tout intérêt à élargir cette même recherche à d'autres genres (pourquoi avoir exclu la chanson de geste ou les fabliaux?) et à d'autres siècles: le $\mathrm{xv}^{\mathrm{e}}$ offrirait, par exemple, le cas extrêmement intéressant de la nouvelle, où le dialogue représente une des structures portantes du récit, ou bien celui des mises en prose, qui permettraient de vérifier sur pièces l'évolution de l'emploi, de l'insertion, des techniques mêmes du dialogue entre XII ${ }^{\mathrm{e}}-\mathrm{XIII}{ }^{\mathrm{e}}$ et $\mathrm{XV}^{\mathrm{e}}-\mathrm{XVI}^{\mathrm{e}}$ siècles. 